\title{
SOBRE LA CONEXIÓN FUNCIONAL ENTRE EL DOLO Y LA CONSCIENCIA DE LA ANTIJURIDICIDAD EN EL DERECHO PENAL CHILENO
}

\section{On the functional connection between intention and wrongdoing-wareness in Chilean Criminal Law}

Juan Pablo Mañalich Raffo *

\begin{abstract}
Resumen: El trabajo ofrece una breve revisión de la tradicional disputa entre la así llamada "teoría del dolo" y la así llamada "teoría de la culpabilidad", dando cuenta de sus diferentes implicaciones en tanto claves de lectura alternativas para la interpretación de los arts. $1^{\circ}$ y $2^{\circ}$ del Código Penal chileno. Para ello se propone una articulación analítica de la conexión funcional entre injusto y culpabilidad, para después clarificar la relación en que se encuentran el dolo y la consciencia de la antijuridicidad. La tesis consiste en que sólo en una atribución de culpabilidad definida por la consciencia de la antijuridicidad se ve plenamente reflejado el eventual carácter doloso del injusto. El resultado de la indagación consiste en una propuesta de reconstrucción de la regulación legal en cuanto al régimen de punibilidad y penalidad aplicable en los casos de error de prohibición vencible, que admite caracterizarse como una defensa de la solución postulada por la teoría del dolo a través del aparato conceptual de la teoría de la culpabilidad.
\end{abstract}

Palabras clave: delito - injusto y culpabilidad - dolo y malicia - error de prohibición.

Abstract: The article provides a brief review of the traditional dispute between the so-called intention theory ("teoría del dolo") and the so-called culpability theory ("teoría de la culpabilidad"), conveying their different implications as alternative frameworks for the interpretation of Articles 1 and 2 of the Chilean Criminal Code. The author suggests the acknowledgment of an analytical-functional connection between wrongdoing ("injusto") and culpability. Afterwards, the author clarifies the relationship between intention and wrongdoing-awareness ("conciencia de la antijuridicidad"). The central thesis hereby is that only in an attribution of culpability defined by wrongdoing-awareness is the intentional character of a given token of wrongdoing properly expressed. This leads to a reconstruction of the legal regulation governing liability and sanctions in cases of avoidable mistake of law ("error de prohibición vencible"). The conclusion reached can be characterized as a defense of the solution postulated by the intention theory throught the conceptual framework of the culpability theory.

Keywords: offense - wrongdoing - culpability - intention - mistake of law.

\footnotetext{
* Abogado, Doctor en Derecho, Profesor asociado del Departamento de Ciencias Penales de la Facultad de Derecho, Universidad de Chile. Correo electrónico: ipmanalich@,derecho.uchile.cl
} 
Mañalich - Sobre la conexión funcional entre el dolo y la consciencia...

\section{Introducción: la lectura de los arts. $1^{\circ}$ y $2^{\circ}$ del Código Penal bajo la teoría del dolo y la teoría de la culpabilidad}

"Tratándose de acciones no permitidas, no hay objeto de error o desconocimiento que sea más importante que, precisamente, su carácter de no permitidas". ${ }^{1}$ Estas palabras de Karl Binding, extraídas del tomo segundo de su monumental Las normas y su contravención, pueden ser especialmente aptas para introducirnos en el tema de esta conferencia. Los requisitos positivos de la imputación de un comportamiento como hecho personalmente delictivo se dejan tematizar, en atención a las circunstancias bajo las cuales dichos presupuestos resultan comprometidos, como presupuestos de determinadas capacidades intencionales: la capacidad de realizar una determinada intención -la de evitar el comportamiento respectivamente antinormativo- y la capacidad de dar prioridad a dicha intención, en el nivel de una intención de segundo orden, como pauta de deliberación práctica. Desde este punto de vista, las palabras de Binding apuntan a una consideración elemental: la capacidad de una persona de realizar, con eficacia para la acción, la intención de evitar el comportamiento antinormativo no puede sino presuponer su capacidad de reconocer la (específica) antinormatividad del comportamiento de cuya evitación intencional se trata. Y en lo que sigue se intentará mostrar cuáles tendrían que ser las implicaciones de dicha consideración para la articulación dogmática de los criterios que afectan los presupuestos cognitivos de las capacidades ya mencionadas, esto es, para la articulación dogmática de las formas de error que pueden operar como razones para la exclusión de la imputación de un comportamiento como hecho personalmente delictivo.

Pero el desafío impuesto por la Comisión Organizadora consiste, además, en contribuir a dar cuenta, por esta vía, de los desarrollos fundamentales que a este respecto ha mostrado la evolución de la tradición dogmática relativa al derecho penal chileno. Y la manera más directa de entrar ello es examinando, preliminarmente, qué es lo que esa tradición ha predicado de la posible regulación de las formas de error con relevancia jurídico-penal que pudiese ser encontrada en el Código Penal chileno.

A este respecto, sin embargo, no es inusual que se sostenga que el Código Penal chileno no contendría regulación alguna de las formas de error con

\footnotetext{
El presente artículo se corresponde con una versión levemente corregida de la ponencia presentada en el marco del Primer Encuentro Estudiantil de Derecho Penal y Política Criminal, celebrado en abril de 2011 en la Facultad de Derecho de la Universidad de Chile. Los planteamientos aquí expuestos se encuentran extraídos de un trabajo más extenso, titulado "El delito como injusto culpable", de reciente publicación en la Revista de Derecho de la Universidad Austral de Chile (Vol. XXIV, 2001, pp. 87-115). Agradezco a Italo Reyes Romero, ayudante ad honorem del Departamento de Ciencias Penales y miembro del comité organizador del referido encuentro, por su muy valiosa ayuda editorial.

${ }^{1}$ Binding, Karl: Die Normen und ihre Übertretung II, 1965 [orig.: 1916], pp. 709 s.
} 
relevancia para la exclusión de la imputación. ${ }^{2}$ Esta afirmación, y aun obviando el hecho de que el inc. $3^{\circ}$ del art. $1^{\circ}$ establece una regla de exclusión de la relevancia del error in personae vel objecto, desconoce que ya en las definiciones fundamentales de sus dos primeros artículos se contienen cláusulas de cuya correcta interpretación depende, efectivamente, cuál sea el estatus de las dos formas de error cuyo contraste aquí interesa. Pues en la discusión tradicional que al respecto existiera en la doctrina chilena, la cuestión ha estado precisamente vinculada a la pregunta acerca de la relación entre las reglas de definición de los arts. $1^{\circ}$ y $2^{\circ}$.

Para dar cuenta de ello es imprescindible tener a la vista en qué consiste la divergencia entre las dos principales construcciones dogmáticas relativas al estatus de una y otra forma de error, que han sido asumidas, históricamente, por los principales exponentes de la doctrina jurídico-penal chilena como "claves de lectura" de los arts. $1^{\circ}$ y $2^{\circ}$ del Código Penal, a saber: la teoría del dolo y la teoría de la culpabilidad. Y aquí puede ser importante notar que la denominación de una y otra construcción responde a la identificación que cada una de ellas hace del presupuesto de imputación susceptible de verse afectado por un error de prohibición.

La teoría del dolo, que tiene como contexto los modelos causalista y neokantiano de construcción del hecho delictivo -y cuyo campeón criollo podría ser identificado con el a mi juicio más grande penalista que haya parido la patria, Eduardo Novoa Monreal-, mantiene que tanto el desconocimiento de las circunstancias del hecho como el desconocimiento de la antijuridicidad del hecho operan excluyendo el dolo como forma de culpabilidad. Y la razón para ello se encuentra, justamente, en la concepción del dolo que es propia de dichos modelos: el dolo es definido como dolus malus, en el sentido de que el mismo integra tanto el conocimiento de las circunstancias de cuya satisfacción depende la realización (no justificada) del tipo delictivo como el conocimiento de la significación jurídicamente delictiva del hecho. La consecuencia fundamental que la teoría del dolo extrae de esto es la siguiente: en la medida en que el error de prohibición siempre excluye el dolo como forma de culpabilidad, el único título de imputación que puede resultar operativo en caso de un error de prohibición vencible es la culpa o imprudencia, siempre que la ley prevea la punibilidad del correspondiente delito imprudente en el ámbito delictivo del cual se trate.

En cambio, la teoría de la culpabilidad, que irrumpe con el advenimiento del modelo finalista de construcción del hecho delictivo -y cuyo más significativo exponente criollo podría ser identificado con quien fuera, por lo demás, el penalista chileno que mayor reconocimiento universal recibiera, Juan Bustos Ramírez-, mantiene que el error acerca de la significación jurídicamente delictiva del hecho opera, eventualmente, excluyendo un presupuesto específico de la atribución de culpabilidad, esto es, la consciencia de la antijuridicidad, mientras que el error acerca de las circunstancias fácticas de las cuales depende la realización del

2 Véase Garrido, Mario: Derecho Penal Parte General II, 2005, p. 307. 
Mañalich - Sobre la conexión funcional entre el dolo y la consciencia...

tipo operaría ya excluyendo el injusto subjetivo del hecho, y no recién la culpabilidad. Esto se explica, igualmente, por la concepción del dolo que hace suya el modelo finalista: el dolo -como también la imprudencia, en su caso- constituye un requisito para la satisfacción del así llamado "tipo subjetivo", el cual, sin embargo, ya no es definido como un dolus malus, sino más bien como un "dolo neutro" o "dolo natural", que no contiene el conocimiento de la antijuridicidad del hecho. Y la exigencia de conocimiento de la antijuridicidad, que en rigor pasa a ser redefinida como la exigencia de un consciencia potencial de la antijuridicidad, queda relegada a ser un presupuesto autónomo de la culpabilidad. La consecuencia fundamental que la teoría de la culpabilidad extrae de esto es la siguiente: en la medida en que el error acerca de la significación jurídicamente delictiva deja intacto el injusto doloso del hecho, dicho error sólo puede operar como eximente de responsabilidad en caso de excluir, por tratarse de un error de prohibición invencible o insuperable, la consciencia potencial de la antijuridicidad; de tratarse, en cambio, sólo de un error vencible o superable, lo único que cabría reconocer sería una atenuación (obligatoria o facultativa) de responsabilidad.

Ahora es posible dar cuenta de cómo la teoría del dolo y la teoría de la culpabilidad se ofrecen como claves de lectura de los arts. $1^{\circ}$ y $2^{\circ}$ del Código Penal. Los partidarios de la teoría del dolo, esto es, de una concepción del dolo según la cual éste abarcaría tanto la representación de las circunstancias del hecho como la representación de la significación jurídicamente delictiva del hecho, han favorecido una interpretación de la definición de "delito" del inc. $1^{\circ}$ del art. $1^{\circ}$ de conformidad con la cual ésta abarcaría únicamente el delito doloso. Esto descansa, a su vez, en la interpretación de la expresión "voluntaria" justamente como exigencia del carácter doloso de la acción u omisión de cuya punibilidad se trata. Y en tales términos, la presunción de voluntariedad establecida en el inc. $2^{\circ}$ del mismo artículo contaría como una presunción (iuris tantum o "simplemente legal") del carácter doloso del hecho. En tal medida, sería recién en el art. $2^{\circ}$ donde se fijarían las bases para la punibilidad del delito imprudente o "cuasidelito". Y fue precisamente bajo esta clave de lectura que tuvo lugar el emblemático reconocimiento de la eficacia eximente del error de prohibición por parte de la Corte de Apelaciones de Santiago el año 1972, por medio de la sentencia redactada por el ministro Rubén Galecio.

En cambio, los partidarios de la teoría de la culpabilidad, esto es, de la concepción de la representación de la significación jurídicamente delictiva del hecho como un presupuesto autónomo de la culpabilidad, diferenciada ésta del dolo "neutro" como componente del injusto subjetivo del hecho, favorecen una interpretación de la definición del inc. $1^{\circ}$ del art. $1^{\circ}$ como comprensiva tanto del delito doloso como del delito imprudente. Ello se funda, a su vez, en la interpretación de la expresión "voluntaria" en el sentido de una exigencia de culpabilidad en sentido estricto, ${ }^{3}$ o bien exclusivamente de la consciencia de la

\footnotetext{
${ }^{3}$ Bustos, Juan y Soto, Eduardo: "Voluntaria significa culpabilidad en sentido restringido", en Revista de Ciencias Penales XXIII, 1964, pp. 243 ss., 258 ss.
} 
antijuridicidad del hecho, ${ }^{4}$ frente a lo cual el art. $2^{\circ}$ reconocería la diferencia específica entre el delito doloso y el delito imprudente en el nivel del correspondiente injusto subjetivo. En tales términos, la presunción (iuris tantum) de voluntariedad funcionaría como una presunción del conocimiento de la antijuridicidad del hecho y no, en cambio, como una presunción de dolo ("neutro"). Y fue bajo esta clave de lectura que la Corte Suprema llegó a postular, recién el año 1998, la eficacia eximente del error de prohibición (invencible), por medio de la también emblemática sentencia redactada por el (entonces) ministro Enrique Cury.

\section{E1 delito como injusto culpable}

Lo que se impone ahora es una revisión de algunas de las implicaciones de una comprensión tradicional del delito como una instancia de injusto culpable. Por "injusto" cabe entender aquí, según ya se sugiriera, una contravención del derecho; más precisamente, una contravención de una determinada norma de comportamiento que reclama validez jurídica. Pero lo distintivo del delito como variante de injusto, a este respecto, está constituido por el carácter reflexivo de esa contravención del derecho. El delito no es una mera contravención, sino más bien contradicción del derecho.

Para que el hecho delictivo se constituya como portador de tal valor declarativo es necesario que el mismo cuente como la expresión objetivada de una falta de seguimiento de la norma correspondiente. Ello presupone, sin embargo, que el autor del hecho haya sido capaz de seguir la norma, de modo tal que en su no-seguimiento se manifieste un déficit reprochable de fidelidad al derecho. Las condiciones de las cuales depende la efectiva capacidad de seguimiento de la norma por parte de su destinatario son identificadas por un conjunto de reglas, que cabe denominar, técnicamente, "reglas de imputación". El hecho resulta imputable, entonces, cuando se satisfacen las condiciones fijadas en las correspondientes reglas de imputación, de las cuales depende que del destinatario de la norma pueda esperarse el seguimiento de ésta, es decir, su reconocimiento práctico como razón eficaz para la acción. ${ }^{5}$ Y la imputabilidad del hecho se articula en un juicio de dos niveles, cada uno de los cuales se corresponde con una dimensión específica de la capacidad de seguimiento de la norma cuyo ejercicio se espera de su destinatario.

Ello hace posible examinar, más de cerca, qué está en juego con la definición tradicional de "delito" como instancia de injusto culpable. A este

\footnotetext{
${ }^{4}$ Así la sugerencia de Cury Urzúa, Enrique: Derecho Penal. Parte General, 2007, pp. 306 s., 446.

${ }^{5}$ En detalle al respecto Kindhäuser, Urs: Gefährdung als Straftat, 1989, pp. 29 ss., 62 ss.; Mañalich, Juan Pablo: Nötigung und Verantwortung, 2009, pp. 46 ss.; Mañalich, Juan Pablo: "Norma e imputación como categorías del hecho punible", en Revista de Estudios de la Justicia N¹2, 2010, pp. 174 ss.
} 
Mañalich - Sobre la conexión funcional entre el dolo y la consciencia...

respecto, Binding terminó inclinándose por la siguiente solución: la especificidad del injusto que es eventualmente delictivo en sentido jurídico-penal no es reconocible como tal con independencia de la culpabilidad. ${ }^{6}$ Ello, porque el valor declarativo del hecho delictivo consiste en la objetivación de una falta de reconocimiento de la norma como razón eficaz para la acción. Y que un hecho llegue a exhibir ese valor declarativo, de modo tal que a su autor pueda reprocharse un déficit de fidelidad a derecho, es en todo caso dependiente de que el hecho le sea definitivamente imputable como quebrantamiento de la norma en cuestión. El injusto que no alcanza a constituir un injusto culpable carece de relevancia jurídico-penal, porque recién la culpabilidad por el injusto fundamenta el carácter reprochable de ese injusto.

\section{Culpabilidad por el injusto}

Es justamente este último punto lo que ofrece la oportunidad para preguntarse acerca de la conexión funcional que ha de reconocerse entre el injusto y la culpabilidad, cuya estructura relacional podría expresarse mediante el enunciado de que el injusto constituye el objeto de referencia de la culpabilidad. Es decir: sólo hay un injusto culpable en la medida en que haya culpabilidad por el injusto.

Ahora bien, la culpabilidad puede ser entendida como el conjunto de los presupuestos de cuya satisfacción depende la imputabilidad definitiva de un comportamiento en tanto hecho expresivo un déficit reprochable de fidelidad al derecho. En esto consiste, precisamente, el énfasis terminológico de la antigua doctrina de la imputación, que identificaba la adscripción de culpabilidad por el hecho con una imputatio iuris. ${ }^{7}$ Pues es recién en virtud de la adscripción de culpabilidad se fundamenta el merecimiento de la específica consecuencia jurídica asociada al quebrantamiento imputable de la norma: el reproche jurídico-penal que se materializa en la (ejecución de la) pena. Y en tanto el derecho penal sea el derecho que regula las condiciones de imposición (y ejecución) de una sanción penal, y en tanto la imposición de una sanción penal -esto es, de una penadependa de la existencia de una infracción de deber reprochable, un injusto que no fundamente el correspondiente reproche, por no resultar personalmente imputable a título de culpabilidad, es un injusto que, como llegara a advertir Binding, carece de toda relevancia jurídico-penal.

Lo anterior puede ser trivialmente obvio, pero tiene consecuencias que están lejos de ser triviales. Aquí es relevante fijarse en una de ellas: el dolo -entendido como consciencia (de las circunstancias) del hecho- que no llega a

\footnotetext{
${ }^{6}$ Binding, Karl: Die Normen und ihre Übertretung I, 1965 [orig.: 1922], pp. 298 s. Al respecto véase Pawlik, Michael: “«¿El paso más importante de la dogmática de la última generación?». Reflexiones para la diferenciación entre injusto y culpabilidad en derecho penal", en del mismo, La libertad institucionalizada. Estudios de filosofía jurídica y derecho penal, 2010, pp. 122 ss.

${ }^{7}$ Fundamental, Hruschka, Joachim: "Reglas de comportamiento y reglas de imputación", en del mismo, Imputación y derecho penal, 2005, pp. 27 ss., 30, 34 s.
} 
fundamentar la correspondiente consciencia de la antijuridicidad del hecho carece de relevancia, al menos directamente, para el reproche de culpabilidad. ${ }^{8} \mathrm{Y}$ como habrá de sostenerse todavía, aquí se encuentra la clave para entender la equiparación que el Código Penal chileno hace, en su art. $2^{\circ}$, de las nociones de "dolo" y "malicia".

En este punto es importante detenerse, con algún cuidado, en la terminología utilizada. La consciencia de la antijuridicidad exigida como condición de culpabilidad es la consciencia de la antijuridicidad del hecho, y no una consciencia de la antijuridicidad "en abstracto". Es decir, la culpabilidad por el injusto exige la representación, por parte del sujeto de la imputación, de que el comportamiento de cuya imputabilidad se trata es contrario a derecho, y esto quiere decir: un comportamiento antinormativo. Esto implica, sin embargo, que sólo en relación con un hecho imputable a título de dolo es posible la constatación de la correspondiente consciencia ("actual") de la antijuridicidad. Pues el dolo y la consciencia de la antijuridicidad se relacionan al modo de una actitud proposicional de primer orden y una actitud proposicional de segundo orden, respectivamente: mientras que actúa con dolo de homicidio quien se representa la posibilidad concreta de que su comportamiento cause la muerte de otro ser humano (sin que se den circunstancias que objetivamente satisfarían el supuesto de hecho de una norma permisiva preferente, como lo sería la permisión relativa a una situación de legítima defensa), actúa con consciencia de la antijuridicidad propia del homicidio quien se representa la posibilidad concreta de que su comportamiento, bajo su descripción como la causación de la muerte de otro, sea contrario a una norma prohibitiva (no desplazada, a su vez, por una norma permisiva preferente). ${ }^{9}$

A esto se sigue que la antinormatividad de un comportamiento es una propiedad superviniente, ${ }^{10}$ o sea, una propiedad secundaria en relación con aquellas propiedades primarias de cuya satisfacción depende que el comportamiento resulte contrario a aquella norma y no resulte, además, cubierto por alguna regla permisiva preferente (constitutiva, en tal medida, de una causa de justificación). Así, la antinormatividad propia de un hecho constitutivo de homicidio es la propiedad secundaria de un comportamiento que soporta una descripción que expresa la satisfacción de las propiedades exigidas por la

\footnotetext{
8 Véase Binding, Karl: Die Normen und ibre Übertretung II (nota 1) 1965 [orig.: 1916], pp. 402 ss., 680 ss., aunque entendiendo el dolo como una forma de culpabilidad que contiene, además del conocimiento de las circunstancias del hecho, el conocimiento de la antijuridicidad del mismo.

9 Para este concepto de actitud proposicional, véase sólo Tugendhat, Ernst: Introducción a la filosofía analitica, 2003, pp. 59 ss., 69 s. Una actitud proposicional es la actitud de un sujeto cuyo objeto es una proposición. La creencia (o bien, la expectativa o el temor) de un sujeto de que su muerte es inminente constituye una actitud proposicional de ese sujeto, cuyo contenido está constituido, a su vez, por la proposición identificada con la expresión "que su muerte es inminente".

${ }^{10} \mathrm{Al}$ respecto Mañalich, Juan Pablo: Nötigung und Verantwortung (nota 5), pp. 41 ss.; Mañalich, Juan Pablo: "Norma e imputación como categorías del hecho punible" (nota 5), pp. 171 s.
} 
Mañalich - Sobre la conexión funcional entre el dolo y la consciencia...

formulación del contenido de la prohibición, es decir, la propiedad de ser un comportamiento que consiste en la causación de la muerte de otro.

Por ende, el desconocimiento de las propiedades primarias del comportamiento que fundamentan su antinormatividad implica, a su vez, el desconocimiento de esa antinormatividad. Quien dispara letalmente contra un ser humano vivo, creyendo erróneamente que se trata de un espantapájaros, necesariamente desconoce la específica antinormatividad de su comportamiento, que es relativa a su descripción (objetiva) como un comportamiento consistente en causar la muerte de otro ser humano. Por eso, todo error de tipo implica un correspondiente error de prohibición, ${ }^{11}$ sin que un error de prohibición, a la inversa, implique un correspondiente error de tipo.

Lo anterior es de interés por dos razones. La primera consiste en que la consciencia ("actual") de la antijuridicidad del hecho siempre faltará tratándose de un injusto (subjetivo) imprudente, incluso en casos de imprudencia consciente, en la medida en que la demarcación entre dolo (eventual) e imprudencia (consciente) se trace con arreglo a un criterio (estrictamente) cognoscitivo. ${ }^{12}$ La segunda razón es la determinante para lo que aquí interesa. Dado que sólo puede haber consciencia ("actual") de la antijuridicidad en relación con un hecho doloso, esto hace posible identificar la precisa función de imputación del dolo, a saber: posibilitar la consciencia de la antijuridicidad como criterio de culpabilidad por el injusto. A esto se reduce la así llamada "función de alerta" (o de "llamada de atención") del dolo. ${ }^{13} \mathrm{Si}$ recién la adscripción de culpabilidad fundamenta el carácter reprochable del hecho, y si el objeto del reproche está constituido por un déficit de fidelidad al derecho manifestado en el no-seguimiento de una norma, entonces el reproche por un no-seguimiento consciente -esto es, doloso- de la norma exige la consciencia (actual) de la antijuridicidad del hecho. Una adscripción de dolo que no llega a fundamentar, en definitiva, una adscripción del correspondiente conocimiento de la antijuridicidad, no es más que la adscripción de un dolo estéril, esto es, de un dolo que carece de relevancia, al menos directa, para el reproche de culpabilidad.

\footnotetext{
11 Véase Jakobs, Günther: Strafrecht Allgemeiner Teil, 1991, 19/34.

12 Ya Binding, Karl: Die Normen und ibre Übertretung II (nota 1), 1965 [orig.: 1916], pp. 314, 325 ss.

${ }^{13}$ En cambio, no es posible fundamentar tal función de alerta en relación con la representación de la falta de realización de las circunstancias de las cuales depende la satisfacción del supuesto de hecho de una causa de justificación, que es precisamente el argumento finalista a favor de la mal llamada "teoría estricta de la culpabilidad", que entiende que la suposición errónea de las circunstancias de las cuales depende la realización del supuesto de hecho de una causa de justificación constituiría un error de prohibición (indirecto), y no un error de tipo (permisivo). Véase el argumento en Welzel, Hans: Derecho Penal Alemán, 1997, p. 199. Concluyentemente en la dirección contraria, y demostrando lo errado de la terminología, Hruschka, Joachim: “¿Realmente es «limitada» la teoría «limitada» de la culpabilidad? Adiós a un debate", en del mismo, Imputación y derecho penal, 2005, pp. 127 ss., 142 s. Al respecto también Mañalich, Juan Pablo: "Consideraciones acerca del error sobre la concurrencia de los presupuestos objetivos de las causas de justificación”, Revista de Estudios de la Justicia $\mathrm{N}^{\circ} 3,2003$, pp. 147 ss., 151 ss.
} 
REJ - Revista de Estudios de la Justicia - No 16 - Año 2012

\section{4. ¿Conocimiento "potencial" de la antijuridicidad?}

Según ya se sostuviera, sólo el conocimiento de las circunstancias de las cuales depende la realización del tipo delictivo pone al agente en posición de formarse la intención de evitar su realización, en pos del seguimiento de la norma. Sobre esta base es correcto mantener, en el sentido de la teoría de la culpabilidad, que el conocimiento de las circunstancias que objetivamente fundamentan la antinormatividad del hecho pertenece a un nivel de imputación que es anterior al nivel de imputación en el cual se hace relevante el conocimiento de la propia antinormatividad del hecho; esto se sigue, en efecto, de la distinción entre el juicio de infracción de deber y el juicio de culpabilidad por la infracción de deber. Pero esto no significa, en modo alguno, que de ello se sigan, con una pretensión de vinculación analítica, las consecuencias institucionales que el legislador puede asociar a esa distinción conceptual.

Aquí hay que notar que existen ordenamientos, como el alemán y el español, que asumen la posibilidad de afirmar una culpabilidad por un hecho doloso prescindiendo de la exigencia de conocimiento ("actual") de la antijuridicidad, haciendo aplicable entonces el régimen de penalidad previsto para el correspondiente delito doloso, sometido a una atenuación facultativa (en el caso alemán) u obligatoria (en el caso español). Tales ordenamientos admiten, en tal medida, un quiebre funcional en referencia a la función de fundamentación de la culpabilidad que desempeña el injusto subjetivo. ${ }^{14} \mathrm{Y}$ por supuesto, no hay obstáculo institucional alguno que hable en contra de tal régimen, dado que el legislador es soberano para equiparar la expresión punitiva de formas de reproche que descansan en criterios de imputación divergentes.

Pero lo que no puede obviarse es la constatación de que bajo tales regímenes legales lo que se establece es, precisamente, una equiparación punitiva de formas de reproche heterogéneas. Pues el reproche por un no-seguimiento consciente (o "a sabiendas") de la norma sólo se deja fundamentar si el sujeto quebranta la norma conociendo ("actualmente") la antinormatividad de su comportamiento. Si el agente no se representa la antijuridicidad del hecho, entonces el quebrantamiento de la norma sólo le es reprochable en virtud de un criterio de imputación extraordinaria, en el sentido de que el carácter vencible del error de prohibición fundamenta la responsabilidad del sujeto por ese mismo error, puesto que el sujeto habría podido evitar, de modo fiel a derecho, su propio déficit de capacidad de seguimiento de la norma. Y nada de esto se ve alterado por la definición eufemística del respectivo requisito de la culpabilidad como un mero "conocimiento potencial" de la antijuridicidad, que fuera impuesta hegemónicamente por el discurso del finalismo. Pues la expresión "conocimiento potencial" no es más que una metáfora que sugiere la inexistencia de

14 Véase Kindhäuser, Urs: “Acerca de la distinción entre error de hecho y error de derecho”, en VV.AA., El error en el derecho penal, 1999, p. 161. 
Mañalich - Sobre la conexión funcional entre el dolo y la consciencia...

conocimiento, asociada a la posibilidad (y exigibilidad) del mismo. ${ }^{15}$ Cuando el requisito por defecto para la atribución de culpabilidad es identificado, dogmáticamente, con un mero "conocimiento potencial" de la antijuridicidad, lo que en efecto se está reconociendo es la aceptación institucional de un criterio de imputación extraordinaria como el criterio de imputación por defecto: el destinatario de la norma no puede invocar su desconocimiento como razón de exoneración en la medida en que a él pueda achacarse haberse puesto en esa situación de déficit de conocimiento.

Para determinar con exactitud el ámbito en que tal criterio de imputación resulta operativo por defecto -al menos en ordenamientos que contemplan reglas como las de los códigos alemán y español-, es imprescindible detenerse en la estructura precisa de la conexión funcional entre dolo y consciencia de la antijuridicidad, para determinar, en primer lugar, bajo qué condiciones cabe reconocer una consciencia "actual" de la antijuridicidad del hecho.

De acuerdo con lo ya sostenido, la consciencia de la antijuridicidad, relevante como criterio de culpabilidad por un injusto doloso, tiene que poder ser entendida como la representación de la específica antinormatividad del hecho que es posibilitada por la representación de las circunstancias fácticas en que consiste, a su vez, el dolo. Pero ello no significa que la representación, por parte del autor, del carácter específicamente antinormativo del hecho, tenga que consistir en aquel conocimiento que es dado por supuesto, a modo de hipótesis, cuando se determina el dolo como criterio de la imputación a título de infracción de deber, esto es, el conocimiento cabal del sentido y alcance de la norma respectiva. Antes bien, para la consciencia ("actual") de la antijuridicidad es suficiente que el autor infiera el carácter específicamente antinormativo del hecho a partir de su conocimiento de las circunstancias fácticas de las cuales depende la realización del tipo. ${ }^{16}$ En la muy acertada formulación de Binding, esto no requiere que el autor llegue a subsumir, en sentido técnico, el hecho bajo el tipo delictivo correspondiente, sino sólo que llegue a la conclusión de que su comportamiento, en atención a las propiedades fácticas (naturales o institucionales) que objetivamente fundamentan su antinormatividad, ha de ser un comportamiento contrario a derecho, precisamente en atención a su descripción como un comportamiento que exhibe esas propiedades. ${ }^{17}$ Es recién en este nivel, y no en el de la determinación del dolo (del hecho) por referencia al conocimiento de las circunstancias fácticas de las cuales depende, objetivamente, la realización del tipo, que cabe recurrir a la así llamada "valoración paralela en la esfera del lego", precisamente en la adscripción del conocimiento de la antijuridicidad. ${ }^{18}$

\footnotetext{
15 Véase Jakobs, Günther: Strafrecht Allgemeiner Teil (nota 11), 19/30.

${ }^{16}$ Kindhäuser, Urs: "Acerca de la distinción entre error de hecho y error de derecho" (nota 14), pp. $161 \mathrm{~s}$.

${ }_{17}$ Binding, Karl: La culpabilidad en derecho penal, 2009, pp. 53 s.

18 Así Kindhäuser, Urs: “Acerca de la distinción entre error de hecho y error de derecho” (nota 14), p. 162.
} 
Y esta consciencia de la específica antinormatividad del hecho, por otra parte, no necesita conllevar una representación rayana en la certeza, sino que es suficiente lo que cabe denominar un "conocimiento eventual de la antijuridicidad". ${ }^{19}$ Lo importante es advertir que esto se sigue, sin más, del reconocimiento de la función indiciaria del dolo. Pues si el dolo, definido en su forma básica como dolo eventual, se satisface con una representación, con un grado de probabilidad relevante para la decisión, de la posibilidad concreta de la realización del tipo delictivo, entonces ese dolo sólo podrá fundamentar una representación equivalente, definida por el mismo grado de probabilidad, del carácter antinormativo del hecho. Para decirlo una vez más con Binding: el conocimiento de la antijuridicidad subsiste, en el caso normal, "a pesar de la duda". ${ }^{20}$

Lo anterior sugiere que la plausibilidad del reconocimiento de un error de prohibición que excluya la consciencia de la antijuridicidad a pesar del carácter doloso del hecho es menor que lo que cabría imaginar a primera vista. Y ciertamente, mientras mayor sea la legitimidad material de la norma quebrantada, en el sentido de que ella constituya una norma autoevidente para el ciudadano, menor será el margen de plausibilidad de la invocación exitosa de un error de prohibición. ${ }^{21}$ Esto explica, entre otras cosas, que el alegato de un error de prohibición siempre muestre mayor verosimilitud, prima facie al menos, tratándose de un extranjero.

\section{Dolo y malicia}

Según ya se mostrara, los ordenamientos que prevén una atenuación (facultativa u obligatoria) de pena en relación con el respectivo hecho doloso cuando existe un error de prohibición vencible en el autor, asumen un quiebre funcional en la fundamentación del reproche de culpabilidad. Pues en tal caso, el carácter doloso del injusto no se expresa en el carácter autoconsciente de la culpabilidad como culpabilidad por ese injusto. Ésta es, precisamente, la consecuencia de todo (genuino) error de prohibición, sea vencible o invencible. Lo característico del error de prohibición vencible se encuentra, más bien, en que el mismo deja subsistente la posibilidad de dirigir un reproche de culpabilidad por el hecho a su autor. Pero ese reproche, mediado por la afirmación del carácter vencible del error, descansa en un juicio de imputación extraordinaria.

\footnotetext{
19 Silva Sánchez, Jesús María: “Observaciones sobre el conocimiento 'eventual' de la antijuridicidad”, en del mismo, Consideraciones sobre la teoría del delito, 1998, pp. 259 ss.

${ }^{20}$ Binding, Karl: La culpabilidad en derecho penal (nota 17), pp. 55 s.

21 A esto se reduce la relevancia heurística de la tradicional contraposición entre hechos constitutivos de mala in se y hechos constitutivos de mala prohibita: la ilicitud de los primeros tendría que poder ser reconocida con total independencia del eventual conocimiento de la respectiva regulación.
} 
Mañalich - Sobre la conexión funcional entre el dolo y la consciencia...

Lo que resta por clarificar es cuál sea el régimen, previsto por el Código Penal chileno, para los casos en que el error de prohibición vencible no se funda en un error de tipo vencible, esto es, en una falta de dolo ("natural") compensada por la imprudencia del autor como criterio de imputación de la infracción de deber a nivel de injusto; es decir, para los casos de error de prohibición vencible en los cuales la falta de consciencia de la antijuridicidad descansa en la falta de inferencia, por parte del autor, del carácter antinormativo del hecho a partir de su efectivo conocimiento de las circunstancias fácticas dadas, que cuenta como el dolo del hecho.

La respuesta parece ser tan clara como categórica: el art. $2^{\circ}$ del Código Penal equipara las nociones de "dolo" y "malicia", con lo cual cabría afirmar que el concepto de dolo hecho suyo por el legislador chileno se corresponde con el concepto de dolo asumido por la tradicional "teoría del dolo": el dolo integraría la consciencia ("actual") de la antijuridicidad del hecho, tal como se lee, por ejemplo, en el Curso de Novoa Monreal. ${ }^{22}$ Pues eso es justamente lo que sugiere la equiparación de los términos "dolo" y "malicia": una definición de dolo como dolus malus. ${ }^{23}$ La consecuencia de ello es conocida. El error de prohibición vencible excluiría el dolo, con lo cual el hecho sólo resultaría imputable a título de imprudencia, cuya punibilidad dependería, entonces, de que la ley prevea, específicamente, la punibilidad del respectivo delito imprudente, lo cual por regla general sólo es el caso tratándose de hechos constitutivos de delitos contra las personas, esto es, tipificados por disposiciones contenidas el Título VIII del Libro II del Código Penal, sin perjuicio de la posibilidad de una declaración específica de la punibilidad del respectivo delito imprudente en algún otro contexto regulativo.

Ésta es, en efecto, la lectura de la regulación legal que resulta de la adopción de la tradicional teoría del dolo. Lo que aquí se ha intentado, sin embargo, es sugerir la posibilidad de una lectura parcialmente discrepante, esto es: una lectura que asuma -en el sentido de la teoría de la culpabilidad- la diferenciación entre dolo y conocimiento de la antijuridicidad desde el punto de vista de su posición relativa en el respectivo nivel de imputación, pero que al mismo tiempo asuma -en el sentido de la teoría del dolo- la necesidad de conocimiento de la antijuridicidad como criterio (ordinario) de culpabilidad por el injusto doloso. Y lo que hay que fundamentar ahora es la plausibilidad de semejante lectura diferenciada, que pretende hacer operativa -con un cierto dejo de ironía - la unidad entre dolo y conocimiento de la antijuridicidad, proclamada por la teoría del dolo, a través de la diferenciación estructural proclamada por la teoría de la culpabilidad, frente a la regulación legal.

\footnotetext{
22 Véase Novoa Monreal, Eduardo: Curso de Derecho Penal Chileno I, 2005, pp. 477 ss., 537 ss., quien validaba, sin embargo, la tesis de una presunción de derecho del conocimiento de la significación jurídica del hecho de conformidad con la regla del art. $8^{\circ}$ del Código Civil.

23 Así Etcheberry, Alfredo: Derecho Penal Parte General I, 1998, pp. 307 s.
} 
Esto, porque si bien el art. $2^{\circ}$ del Código Penal parece equiparar, sin más, las nociones de dolo y malicia, esta equiparación parece relativizarse en otros sectores de la regulación legal, fundamentalmente en aquellas disposiciones que expresamente incorporan una exigencia específica de "malicia", aunque jamás de "dolo". Si "dolo" y "malicia" no fueran más que términos estrictamente sinónimos para el legislador, entonces semejante exigencia expresa de "malicia" no sería sino una redundancia. Pues, dado que la exigencia general de dolo opera por defecto, en virtud de la clausura de la punibilidad del delito imprudente o "cuasidelito" (art. 10 $\mathrm{N}^{\circ} 13 \mathrm{CP}$ ), la exigencia específica de "malicia" resultaría enteramente superflua. ${ }^{24}$

Frente a esto cabría sugerir una interpretación alternativa, que procure relativizar la tesis de una estricta equivalencia entre las nociones legales de "dolo" y "malicia". Para ello, es de máxima relevancia considerar el problema en referencia al art. 342 del Código Penal, que tipifica las variantes típicas de aborto cuya realización es imputable, a personas distintas de la mujer embarazada, a título de dolo. El encabezado del art. 342 exige, en efecto, que el hecho sea cometido "maliciosamente". Puesto que el aborto, en virtud de su sola posición en el sistema de la regulación legal, no se encuentra configurado como una forma de delito contra las personas, no es admisible una interpretación de "maliciosamente" como equivalente a "dolosamente", pues ello implicaría la adscripción de una redundancia al legislador. Esto deja abierta la posibilidad de interpretar el término "maliciosamente", en el contexto del art. 342, como una exigencia específica de conocimiento de la antijuridicidad. Y lo interesante está en que hay buenas razones por las cuales el legislador pudo haber juzgado necesario o conveniente establecer tal exigencia específica.

Esto concierne directamente el estatus de la prohibición del aborto como una norma que está lejos de ser autoevidente para el ciudadano. Sobre todo en atención a la altísima conflictividad que esa prohibición muestra en relación con el reconocimiento del estatus de persona de la mujer embarazada, es altamente probable que, a pesar del dolo ("natural"), el autor del hecho pueda no llegar a inferir su específica antinormatividad, ante todo en virtud de una eventual suposición errónea de la existencia de causas de justificación, es decir, en virtud de un posible error de prohibición indirecto (o "error de permisión"). ${ }^{25}$ En este contexto, la exigencia expresa de "malicia" tendría que entenderse como una declaración legal de una exigencia de conocimiento de la antijuridicidad como requisito de la punibilidad del hecho, cuya satisfacción ha de ser exitosamente demostrada por el órgano persecutor.

\footnotetext{
24 Acerca de esta posibilidad interpretativa véase ya Amunátegui, Felipe: "Maliciosamente” y "A Sabiendas" en el Código Penal Chileno, 1961, pp. 46 s.

${ }^{25}$ Indiciariamente en este sentido, Etcheberry, Alfredo: Derecho Penal Parte General I (nota 23), p. 308.
} 
Mañalich - Sobre la conexión funcional entre el dolo y la consciencia...

\section{Error de prohibición vencible e imprudencia}

La pregunta cuya respuesta aún está pendiente es la siguiente: ¿cuál es el régimen que el Código Penal chileno hace aplicable para los casos de error de prohibición vencible? El punto de partida se halla en la consideración de que la equiparación de las nociones de "dolo" y "malicia", en el contexto del art. $2^{\circ}$, no tiene que ser entendida como una declaración de equivalencia semántica, sino más bien como una indicación de la conexión funcional que cabe reconocer entre el dolo y el conocimiento de la antijuridicidad, esto es, entre dolo y malicia, ${ }^{26}$ justamente en el sentido de que la culpabilidad en que se refleja el carácter doloso del hecho sólo puede consistir en una culpabilidad definida por el conocimiento de la antijuridicidad del hecho. Y esta forma de culpabilidad, la única funcionalmente congruente con el injusto subjetivo de un hecho doloso, puede ser entendida, a su vez, como la específica "voluntariedad", en los términos de la definición del inc. $1^{\circ}$ del art. $1^{\circ}$, del hecho constitutivo de un delito doloso. ${ }^{27}$

Pero de acuerdo con la regla del inciso $2^{\circ}$ del art. $1^{\circ}$, el hecho ha de reputarse voluntario, salvo que conste lo contrario; es decir, el hecho doloso, en el sentido del art. $2^{\circ}$, ha de reputarse malicioso, salvo que se demuestre lo contrario. Luego, el régimen general de la regulación del Código Penal en relación con los presupuestos de la culpabilidad propia del delito doloso -que sólo se ve alterado allí donde la ley exige, expresamente, "malicia"- convierte el conocimiento de la antijuridicidad en objeto de una presunción simplemente legal, tal como célebremente lo sostuviera, en un tan importante como temprano artículo, Juan Bustos Ramírez, en coautoría con un otrora profesor de derecho administrativo de esta Facultad, cuyo primer apellido es Soto, pero cuyo segundo apellido no es Piñeiro, de modo tal que lo podemos omitir). ${ }^{28} \mathrm{Y}$ dicha presunción sólo resultará derrotada en la medida en que la defensa demuestre exitosamente la existencia de un error de prohibición. Si éste resulta ser un error vencible, entonces, excluyéndose el carácter malicioso del hecho, la punibilidad del mismo quedará sometida al régimen del delito imprudente: a menos que la ley prevea la punibilidad específica de la correspondiente forma de comisión imprudente, el hecho sólo resultará punible si el mismo se encuentra tipificado bajo el Título VIII del Libro II del Código Penal, con arreglo a los arts. 490 y siguientes, que justamente exigen la inexistencia de "malicia", y no meramente la inexistencia de "dolo" para la punibilidad del respectivo "cuasidelito".

\footnotetext{
${ }^{26}$ Esto es apenas sugerido por Garrido, Mario: Derecho Penal Parte General II (nota 2), pp. 106 s., aunque apoyándose en el escasamente concluyente argumento de que la conjunción "o" que conecta los términos "dolo" y "malicia" sería "alternativa y no equiparativa". El problema es que esto es lo que debería ser demostrado, y no dado por sentado, por el argumento.

27 Con ello, la exigencia de voluntariedad del art. $1^{\circ}$ conserva su carácter común frente a la distinción legal entre el delito doloso y el delito imprudente, formulada en el art. $2^{\circ}$. Fundamental para esta interpretación, Bustos, Juan y Soto, Eduardo: "Voluntaria significa culpabilidad en sentido restringido" (nota 3), pp. 243 ss., 260 s.

28 Ibid., p. 261.
} 
REJ - Revista de Estudios de la Justicia - No 16 - Año 2012

La solución general que, por defecto, prevé el Código Penal para los casos de error de prohibición vencible consiste, entonces, en la exclusión del régimen de penalidad asociado a la exigencia de culpabilidad por un injusto doloso -esto es, de aquella que presupone una atribución de culpabilidad en la cual se refleja el carácter doloso del injusto (subjetivo)-, subsistiendo únicamente la aplicabilidad del régimen de penalidad correspondiente a la culpabilidad referida a un injusto imprudente, siempre que la ley prevea la punibilidad del hecho imputable a título de imprudencia en el ámbito delictivo correspondiente. La defensa de esta solución podrá parecer revisionista, pero ella no es más que la expresión de la referencia (funcional) de la culpabilidad al injusto. Pues en una culpabilidad no definida por el conocimiento de la antijuridicidad no se manifiesta el carácter doloso del injusto, en circunstancias de que la manifestación del injusto doloso en la culpabilidad es lo único que puede fundamentar su mayor reprochabilidad. Y esto tendría que contar como desiderátum para cualquier concepción que pretenda poder seguir entendiendo el delito como lo que es: "auto-realización de la culpabilidad". ${ }^{29}$

${ }^{29}$ Binding, Karl: Die Normen und ibre Übertretung II (nota 1), 1965 [orig.: 1922], p. 293. 
Mañalich - Sobre la conexión funcional entre el dolo y la consciencia...

\section{BIBLIOGRAFÍA}

* AMUNÁtegui, F.: "Maliciosamente” y “A Sabiendas” en el Código Penal Chileno, Ed. Jurídica de Chile, Santiago, 1961.

* BINDING, K.: Die Normen und ibre Übertretung II, 2ª ed., Scientia Verlag, Aalen, 1965 [orig.: 1916].

1922].

Die Normen und ihre Übertretung I, $4^{\mathrm{a}}$ ed., Scientia Verlag, Aalen, 1965 [orig.:

, La culpabilidad en derecho penal, BdF, Montevideo/Buenos Aires, 2009.

* BUSTOS, J. y SOTO, E.: "Voluntaria significa culpabilidad en sentido restringido", en Revista de Ciencias Penales XXIII, 1964.

* CURY Urzúa, E.: Derecho Penal. Parte General, $7^{a}$ Edición, Ediciones Universidad Católica de Chile, Santiago, 2007.

* ETCheberry, A.: Derecho Penal Parte General I, $3^{a}$ ed., Editorial Jurídica de Chile, Santiago, 1998.

* Garrido, M.: Derecho Penal Parte General II, 4a ed., Editorial Jurídica de Chile, Santiago, 2005.

* HRUSCHKA, J.: “¿Realmente es «limitada» la teoría «limitada» de la culpabilidad? Adiós a un debate", en del mismo, Imputación y derecho penal, Thomson/Aranzadi, Navarra, 2005.

, "Reglas de comportamiento y reglas de imputación", en del mismo, Imputación y derecho penal, Thomson/Aranzadi, Navarra, 2005.

* JAKOBS, G. Strafrecht Allgemeiner Teil, 2a ed., Walter de Gruyter, Berlín, 1991.

* KINDHÄUSER, U.: "Acerca de la distinción entre error de hecho y error de derecho", en VV.AA., El error en el derecho penal, AdHoc, Buenos Aires, 1999.

Gefährdung als Straftat, Vittorio Klostermann, Frankfurt a. M., 1989.

* MAÑALICH, J. P.: "Consideraciones acerca del error sobre la concurrencia de los presupuestos objetivos de las causas de justificación”, Revista de Estudios de la Justicia $\mathrm{N}^{\circ} 3$, 2003.

"Norma e imputación como categorías del hecho punible", en Revista de Estudios de la Justicia $\mathrm{N}^{\circ}$ 12, 2010.

Nötigung und Verantwortung, Nomos, Baden-Baden, 2009.

* NOVOA Monreal, E.: Curso de Derecho Penal Chileno I, $3^{a}$ ed., Editorial Jurídica de Chile, Santiago, 2005.

* PAWLIK, M.: “«El paso más importante de la dogmática de la última generación?». Reflexiones para la diferenciación entre injusto y culpabilidad en derecho penal", en del mismo, La libertad institucionalizada. Estudios de filosofía juridica y derecho penal, Marcial Pons, Madrid/Barcelona/Buenos Aires, 2010.

* SILVA Sánchez, J. M.: “Observaciones sobre el conocimiento 'eventual' de la antijuridicidad", en del mismo, Consideraciones sobre la teoría del delito, Ad-Hoc, Buenos Aires, 1998.

* TUGENDHAT, E.: Introducción a la filosofía analítica, Gedisa, Barcelona, 2003.

* WelZEL, H.: Derecho Penal Alemán, 4a ed., Ed. Jurídica de Chile, Santiago, 1997. 